\title{
De España al Carajá: el hispanismo en La Novela del Indio Tupinamba de Eugenio F. Granell
}

\author{
From Spain to Carajá: Hispanism in La Novela del Indio Tupinamba \\ by Eugenio F. Granell
}

\section{Azahara Palomeque Recio}

\author{
Princeton University \\ Department of Spanish and Portuguese \\ apalomeq@princeton.edu
}

[recibido 28/10/2014, aceptado 26/01/2015]

\section{RESUMEN}

Este trabajo analiza La Novela del Indio Tupinamba (1959) del escritor gallego, militante del POUM y exiliado tras la Guerra Civil española, Eugenio Granell, teniendo en cuenta su intervención en el campo de la producción cultural (Bourdieu) a partir de la crítica que efectúa del "imperialismo discursivo" (Díaz Quiñones), denominado "hispanismo", que ha caracterizado tradicionalmente las relaciones entre España y sus antiguas colonias.

PALABRAS ClaVE: Eugenio Granell, hispanismo, imperialismo, Guerra Civil española, exilio.

\section{RESUMO}

Este traballo analiza La Novela del Indio Tupinamba (1959) do escritor galego e militante do POUM Eugenio Granell, exiliado ó cabo da Guerra Civil española, considerando a súa intervención no campo de produción cultural (Bourdieu) e a súa crítica do "imperialismo discursivo" (Díaz Quiñones), denominado "hispanismo", que caracterizou tradicionalmente as relacións entre España e as súas antigas colonias*.

PALABRAS CHAVE: Eugenio Granell, hispanismo, imperialismo, Guerra civil española, exilio.

\section{ABSTRACT}

This article analyzes La Novela del Indio Tupinamba (1959) by the Galician writer Eugenio Granell, who was affiliated with the POUM party and exiled after the Spanish Civil War. The article takes into consideration his intervention into the field of cultural production (Bourdieu), starting with his critique of the "discursive imperialism" (Díaz Quiñones), called "hispanism", which has traditionally characterized the relationship between Spain and its former colonies.

KEY WORDS: Eugenio Granell, hispanism, imperialism, Spanish Civil War, exile.

Palomeque Recio, A. (2015): “De España al Carajá: el hispanismo en La Novela del Indio Tupinamba de Eugenio F. Granell”, Madrygal (Madr.), 18, Núm. Especial: 115-125.

SUMARIO: 1. Introducción. 2. Hispanismo vs. hispanidad. 3. El campo cultural: una crítica a dos bandos. 4. "Un mundo hispánico a la deriva". 5. Referencias bibliográficas.

\footnotetext{
* Agradezco al profesor Germán Labrador y al poeta Juan Bello su ayuda en la traducción al gallego de este resumen.
} 


\section{INTRODUCCIÓN}

La Novela del Indio Tupinamba (1959) es conocida comúnmente por ser la gran creación ficcional surrealista sobre la Guerra Civil española. Esto se debe, probablemente, a la aplicación de dicha categorización estética e histórica por parte de la crítica que primeramente descubrió el libro: tanto en la nota introductoria que en 1957 redactaba Vicente Llorens como carta de presentación del mismo, publicado dos años más tarde en México, así como en la que posiblemente constituya la primera referencia a la obra en España, de la mano de José Marra López (1963: 506), se la caracteriza de esta forma. Estudios posteriores, no obstante, han demostrado con solvencia argumental la complejidad de una creación que, si bien efectúa, partiendo del legado de Breton, alusiones explícitas a la contienda intestina que tuvo lugar entre 1936 y 1939, se desarrolla en su plenitud en un espectro temporal, espacial y temático más amplio que abarcaría no sólo la guerra, sino, a partir de ella, las relaciones culturales entre España -tanto la franquista como la republicana- y Latinoamérica durante el exilio, y una revisión de la historia española a partir de las referencias a su carácter colonial.

Partiendo de la polisemia resultante de la obra, este artículo analiza ciertos pasajes de la novela intrínsecamente relacionados con la historia colonial y postcolonial española y latinoamericana, con especial atención a aquellos en los que el autor trabaja con una crítica a la relación de dominio simbólico y cultural entre los territorios anteriores que ha venido a denominarse "hispanismo". Para ello, se investigarán las aventuras y desventuras de su protagonista, el Indio Tupinamba, en la España en guerra y en el lugar elegido para su exilio, la metonímica República Occidental del Carajá, con el fin de dilucidar el cuestionamiento que efectúa Granell del campo de producción cultural español en relación a su capacidad para convocar el corpus discursivo del hispanismo en su espectro político más amplio.

\section{HISPANISMO VS. HISPANIDAD}

Para comprender mejor el fenómeno del hispanismo, es necesario remontarnos -al menos-a 1892, época en la que se visibiliza una suerte de reconstrucción simbólica de Latinoamérica ejercida desde España a partir de la celebración del cuarto centenario del inicio de la campaña de dominación colonialista (Loureiro 2003: 68). Alrededor de esta fecha, e in crescendo hasta alcanzar su vértice en 1898 (año de la pérdida de Cuba, Puerto Rico y Filipinas), algunos sectores de la intelectualidad española comparten una visión de la historia de España como tripartita. A saber, ésta se divide en una gloria pasada (1492 en adelante); una decadencia creciente a partir del siglo XVII que alcanza su cenit en 1898; y una gloria futura, para cuya aprehensión se recurre a la primera etapa: el discurso se remonta a la época de las empresas coloniales. En estos tres periodos - o retóricas- confluyen las nociones de orgullo nacional y decadencia que, según Ángel Loureiro, fueron fundamentales para el nacionalismo decimonónico español y para la construcción simbólica de Latinoamérica, puesto que de ellas se infiere una "excepcionalidad" española que servirá para justificar el rol civilizatorio de España en las colonias (2003: 67), especialmente después de 1898. Este "rol civilizatorio" es la base de lo que se entiende por hispanismo.

El hispanismo es asimismo una ideología. Ésta se fundamenta en la creencia en una suerte de unidad entre España y sus antiguas colonias, reunidas no sólo en lo espiritual, sino también en lo histórico, lo lingüístico y lo biológico (dentro de lo cual la categoría de raza juega un rol predominante). Parte de una visión totalizadora de la historia -en la legitimación y uso de una "historia global" concebida como línea unificadora en la que desembocan distintas disciplinas sometidas a una misma teleología (Foucault 2007: 15)- que estriba en la continuidad entre "madre patria" e "hijos" colonizados a pesar de la desaparición del denominado "imperio", puesto que los lazos entre ambas, más que romperse en 1898, experimentan una metamorfosis de lo material a lo espiritual. La ligazón entre estos territorios presupondría el tutelaje de España respecto a las otras naciones y se presenta como una fuerza simbólica fundamentada en el pasado, creada para contrarrestar de forma espiritual la supremacía presente de Estados Unidos y 
de algunas potencias europeas en el panorama internacional de la época, y para compensar por ello.

Es importante destacar el carácter bidireccional que asume el hispanismo. En palabras de Loureiro: "the role of culture as a unifying factor found many echoes and followers among Spanish American intellectuals" (2003: 71), tratándose por lo tanto de un corpus discursivo que contó con el apoyo de parte de la élite latinoamericana, como vía para ascender en la escala social y/o simbólica, como se va a criticar, de facto, en La Novela del Indio Tupinamba. Arcadio Díaz Quiñones desarrolla esta cuestión más en profundidad cuando estudia el caso de Rubén Darío, quien "se dedicó con ahínco a proclamar su adhesión a la cultura española" (2006: 126), en tanto que usaba este vínculo para su legitimación como intelectual enarbolando un proyecto nuevo. En otros casos, la adhesión a la cultura española dominante se efectúa con matices que favorecen la diferenciación del sujeto tanto del contingente colonial como del viejo imperio: el hombre de la clase criolla usa la genealogía peninsular como herramienta de poder político, al mismo tiempo que su nacimiento en suelo colonial le permite ser distinto a lo español, según Díaz Quiñones (2006: 104). El autor afirma que el hispanismo fue usado tanto por republicanos como por el régimen franquista, si bien de forma distinta (2006: 155). Las aseveraciones anteriores demuestran la ductilidad del hispanismo, su capacidad para amoldarse a distintos proyectos político-culturales como herramienta de creación de prestigio en el campo cultural, como se detallará en lo sucesivo.

Este discurso de dominación simbólica, cultural y política se perpetúa en el tiempo hasta la detonación de la Guerra Civil tanto entre el bando de los sublevados como entre los leales a la II República española, llegando a formar parte de sus retóricas oficiales durante y después de la conflagración ${ }^{1}$. En el caso de la facción rebelde, acabada la guerra, el hispanismo pasó a formar parte de un corpus discursivo radicado en los valores coloniales de la conquista y la evangelización que se convertiría en estandarte ideológico de la dictadura con el nombre de "hispanidad". Como explica Santiago Juan Navarro, la particularidad utópica de la hispanidad franquista funciona como instrumento legitimador de una política exterior volcada al establecimiento de lazos culturales y diplomáticos con la antigua América española. En su ejercicio interviene un imperialismo de cariz dicotómico: por una parte, éste se conforma como artilugio ideológico que permite al Régimen ejercer de "centinela de Occidente" de manera espiritual, frente a otras naciones más avanzadas económicamente; por otra parte, se trataba de un imperialismo nostálgico cuyo carácter paradójico era evidente, ya que "implicaba el reconocimiento de la propia debilidad presente". La retórica en que estriba el mito de la hispanidad ha sido juzgada por Navarro como un "éxito propagandístico", en cuanto que posibilitó la institucionalización del Día de la Raza (posteriormente Día de la Hispanidad, en vigor hasta ahora); la creación de una industria cultural que promoviese los valores "hispánicos" a través de distintas plataformas y soportes culturales; y la implementación del Instituto de Cultura Hispánica en 1945, heredero del anterior Consejo de la Hispanidad y principal herramienta ideológica del Régimen a la hora de crear o fortalecer vínculos culturales con los antiguos territorios transatlánticos dominados (2006: 395-97) ${ }^{2}$.

El uso del hispanismo por buena parte del contingente intelectual republicano ha despertado el interés de algunos estudiosos, entre los que destaca Sebastiaan Faber. El crítico ha analizado la conflictividad ideológica de

\footnotetext{
${ }^{1}$ El libro de Fredrick Pike ofrece un examen detallado de la evolución del hispanismo desde finales del siglo XIX hasta la época de la Guerra Civil.

${ }^{2}$ Para indagar en las funciones y el desarrollo del Instituto de Cultura Hispánica, puede consultarse el estudio de María Escudero (1994).
} 
ciertos exiliados republicanos por arrogarse una hegemonía cultural que los situase moralmente por encima de la retórica hispanista franquista. De acuerdo con Faber, buena parte de los dos bandos implicados en la contienda participaron de una concepción de la cultura española como ente espiritual compartido por las colonias que, teniendo como elemento unificador el lenguaje, implicaba la existencia de un destino común para ambos territorios y buscaba el reconocimiento global de una nueva gloria hispánica. Ambos tipos de hispanismo -el franquista y el republicano- presuponían alguna forma de paternalismo o "tutelaje" respecto a las distintas naciones latinoamericanas, si bien el hispanismo de índole progresista era más susceptible de conceder cierta autonomía a América Latina en su proceso de construcción cultural e identitaria. Como ejemplos de productores de discurso hispanista destaca la obra del poeta surrealista Juan Larrea, quien en la revista España Peregrina aseveró su creencia en la misión de los exiliados españoles consistente en llevar la esencia hispana desde España a tierras transatlánticas con el propósito de que ambas configuraran una suerte de hegemonía espiritual mundial. La definición de la identidad española a partir de una esencia eterna desde los tiempos prerromanos que sostiene Menéndez Pidal, o bien fundamentada en particulares circunstancias históricas en la pluma de Américo Castro, representarían asimismo una raigambre española de que Latinoamérica sería deudora (Faber 2000: 173-77).

El fenómeno del hispanismo tanto en la España franquista como en la republicana del exilio forma parte de lo que Faber ha llamado "nacionalismo cultural": un salvavidas ideológico al que recurrir cuando el sentimiento de identidad colectiva se presagia amenazado (2000: 177). El término se construye como paradoja puesto que estriba en una concepción de la nación que abraza territorios y colectivos no pertenecientes a ella con fines inclusivos. Edward Said reflexiona sobre las relaciones entre nacionalismo y exilio, localizando éste último en un estado de discontinuidad con la nación consistente en un cercenamiento temporal, físico, genésico que, sin embargo, no por ello rehusa efectuar una reorganización simbólica de aquellos elementos perdidos: "exiles feel, therefore, an urgent need to reconstitute their broken lives, usually by choosing to see themselves as part of a triumphan ideology or a restored people" (2000: 177). Esta ideología triunfante desempeñaría una función generadora de identidad colectiva a través de la búsqueda de lo que en otras circunstancias la nación-Estado provee: un sentimiento de pertenencia.

En este contexto el hispanismo en el exilio puede ser considerado como elemento compensatorio por el vacío dejado por la deslocalización territorial y política. Fuera de la nación, el exiliado realiza una labor de reconstrucción histórica, lingüística, mitológica, que, según Said, conduce a productivas indagaciones sobre el yo que, no obstante, pueden llegar a promover "strident ethnocentrism". Si bien éste fue el caso de los exiliados republicanos que abrazaron la ideología del hispanismo con el fin de recomponer la patria perdida, Said advierte que la particularidad mayor del desarraigo consiste en la capacidad creativa para engendrar otros mundos posibles a partir de la ausencia de aquél de referencia. En este sentido, las obras de los escritores exiliados suelen ser originales o innovadoras ya que "exiles cross borders, break barriers of thought and experience" (2000: 184-85). Quizá sea esta amplitud de pensamiento que otorga la ruptura con el lugar de origen lo que indujo a Granell a escribir $L a$ Novela en la que, como se argumentará, se produce un trabajo de resemantización de los vínculos simbólicos entre España y Latinoamérica junto a una crítica del hispanismo en varios flancos del espectro político durante y después de la Guerra Civil.

\section{EL CAMPO CULTURAL: UNA CRÍ- TICA A DOS BANDOS}

El nexo con América Latina lo desarrolla Eugenio Granell por propia experiencia vital. Afiliado a la izquierda trotskista del POUM (Partido Obrero de Unificación Marxista), tras el derrocamiento de la República en 1939, el escritor fue detenido dos veces antes de emprender su viaje al exilio: la primera, 
por las derechas republicanas; la segunda, por lo que Francisco Tovar ha denominado la "facción estalinista" de la guerra, es decir, aquella controlada por el partido comunista (2001: 11). Después de una breve estancia en campos de concentración franceses, Granell consigue, en 1940, desplazarse a la República Dominicana, que en aquella época se encontraba bajo el mando del dictador Rafael Leónidas Truji1lo. Paradójicamente, en tierras transatlánticas encuentra el literato gallego un régimen que posee más similitudes con el de Franco que las que hubiera deseado, lo que le incita a dejar el país y dirigirse a Guatemala en 1946. Esta estancia resultó igualmente infructuosa, puesto que debido a una serie de fricciones surgidas entre grupos de tendencia comunista y el literato, éste se ve obligado a marchar a Puerto Rico en 1950. Aquí publicará Isla, Cofre Mitico (1951), obra en la que ya se puede vislumbrar su interés por indagar en "el espacio y las huellas del colonialismo isleño" (Tovar 2001: 20). Finalmente, en 1957, Granell se establece en Nueva York como profesor del Brooklyn College, estancia que durará hasta 1985, año de su regreso a España. La redacción de $L a$ Novela del Indio Tupinamba probablemente se produjera con anterioridad a su llegada a los Estados Unidos, dada la introducción que para ella escribe Vicente Llorens en 1957, ya mencionada.

La Novela produce, ya desde el principio, un efecto de distanciamiento en el lector en cuanto que comienza con una fotografía del Indio Tupinamba, al que se le adjudica la categoría de "autor", junto a una imagen adyacente de un supuesto "redactor". Si bien no se realiza mención a estas funciones durante el grueso del libro, la advertencia del paratexto fotográfico sitúa al lector ante un desdoblamiento primero del discurso que remite directamente a la forma en que han sido elaborados tradicionalmente testimonios subalternos, incluidos los indígenas durante la época colonial española. La imagen del redactor invoca la presencia de un intermediario, un traductor cultural que condiciona la autonomía del autor al mismo tiempo que interviene entre su palabra y el resultado final de la obra escrita. La mediación cultural es llevada al terreno de lo escenográfico en el primer capítulo al ser utilizado un bloque de libros como columna tras la que esconder los cuerpos en un juego que protagonizan un "Señor" y el "Dueño" de una librería donde los tomos se encuentran. En el segundo capítulo se revelan las identidades de los personajes: el Dueño es el Indio Tupinamba, al que con esta caracterización se le atribuye un corpus cultural propio; el Señor es "nada menos que un Conquistador español de los de América". Tras quemar el Indio los volúmenes de su librería, entra en el local un "Cura", quien bautizará al indígena mientras el Conquistador le corta la cabeza varias veces sin éxito en darle muerte, ya que el Indio tiene la capacidad de ajustarla a su cuerpo de nuevo. Poco después se descubre el contexto de la escena: se trata de la Guerra Civil española, en la que "las gentes pudientes sublevadas habían tomado por su jefe al pequeño Gran Turco" (1996: 15-19), en clara referencia a Franco.

En estas primeras páginas Granell expone los elementos que van a ser polemizados a lo largo de la narración: la historia de España, vista desde la óptica de la dominación y la violencia de Estado a través de una primera analogía entre los procesos de opresión colonial y los de la Guerra Civil; la religión católica como agente de las dinámicas de subyugación; la voz de un personaje perturbador como el Indio Tupinamba encargado de indagar en estos procesos socio-políticos; y la cultura escrita como herramienta para la construcción de la historia. La hoguera que los ejemplares alimentan evoca tanto el imaginario inquisitorial como una práctica que, durante la Guerra Civil, "se convirtió en un acto público de adhesión al bando nacional" (Boza y Sánchez 2007: 83), al mismo tiempo que subvierte sus connotaciones conservadoras en cuanto que es el Indio el propietario de la librería y aquél que inicia el fuego. Con este acto, el protagonista se apropia de la violencia histórica de la quema para enfatizar la necesidad de destruir la cultura occidental, a saber, de reescribir la historia. Si, a decir de Luis Moreno, los personajes del Conquistador y el Indio remiten directamente a la violencia de la historia española y es tal motivo lo que confiere unidad temática a la novela (2009: 168), destaca asimismo el poder de la cultura letrada en la configuración de dicha historia. 
La Guerra Civil y el posterior exilio van a ser elaborados por Granell como lugares ficcionales en los que tiene lugar una disputa socio-política por el significado de la cultura, $\mathrm{y}$ en los que las relaciones (post)coloniales van a desempeñar un rol predominante como discursos legitimadores. Proveniente del partido más desprestigiado de la contienda, Granell dirige su crítica mordaz a distintos perfiles del campo de producción cultural, definido por Pierre Bourdieu como aquel campo de fuerzas con un determinado número de posiciones disponibles que se articula, a su vez, como campo de batalla para conservar o transformar ese campo de fuerzas (1993: 30). Aunque el campo de producción cultural es independiente de otros en los que se divide la estructura social-económico, político, etc.-, actúa en relación con ellos, por lo que las luchas internas del primero pueden encontrar una correspondencia con las luchas externas entre clases o distintos colectivos sociales. Asimismo, para que se produzca un cambio significativo en las relaciones de poder del campo, es necesaria la existencia de cambios externos relevantes de tipo político, bélico y/o revolucionario (1993: 57-58). En este sentido, Granell explora la dislocación del campo cultural que supuso la guerra civil articulando sus consecuencias en la longue durée, y en su más amplia abarcadura política.

Una de las mudanzas más representativas del panorama literario español de la época fue el surgimiento de una corriente intelectual que abandonó progresivamente la vanguardia de los años veinte, para reivindicar un tipo de literatura popular favorable a la causa republicana durante la guerra. Consciente de este giro cultural, Granell dedica su tercer capítulo a "la Unión de los Intelectuales", referencia explícita a la Alianza de Intelectuales Antifascistas, grupo fundado en 1936 del que formaban parte, entre otros, los escritores Rafael Alberti y María Teresa León, cuyas identidades en La Novela corresponden a los personajes "Adonis Ruzafa" y "María Tancreda". En esta sección del libro, el autor problematiza la noción de pueblo que estaba vigente entre la intelectualidad de la Alianza - en buena parte comunista-, cuestionando ciertos elementos populares que se valoraban en este contexto. El Cura, aterrado por la guerra, busca refugio en el Palacio que servía de sede a los intelectuales, apelando a su identidad como "poeta del pueblo". Ésta la ha conseguido tras vestir "un pantalón de picador de toros" y escribir un romance "exactamente igual a los millares de romances escritos por los españoles y los hispanoamericanos desde que los dejaron de escribir los moriscos: una mamarrachada". Junto a su atuendo y a su labor poética, la comparación que efectúa de los cañonazos con "cuescos" promueve su aclamación entre el grupo como "Héroe Poeta y Campesino" (1996: 21-23). Valiéndose del humor, Granell critica una noción de cultura que Faber afirma común entre algunos republicanos: aquélla en la que el espíritu de la nación reside en la vida del pueblo llano (2002: 87). Por otra parte, la validez de las letras españolas es localizada en una etapa anterior a la que, según la discursividad hispanista, constituye la época de la fundación de la modernidad española: el Siglo de Oro, coincidente con el de la expansión colonial.

La interrelación entre el discurso hispanista y la empresa cultural republicana es satirizada en los capítulos que constituyen el exilio del Indio Tupinamba en la República del Carajá. El protagonista había decidido previamente casarse con la gitana española Carmensiya, en un acto que es construido como subversión del proceso de poblamiento colonial latinoamericano puesto que el lector sabe de su intención de tener "mestizos" (1996: 89). Constituida la pareja, deciden marchar al Carajá, donde observan un proceso de reconstrucción de las tierras recién pisadas por parte de los exiliados que a ella arriban. Se trata de la erección de una serie de monumentos, réplica de europeos, entre los que destacan: "un puente levadizo, una imitación perfecta de la Torre de Pisa y otra de los Leones de la Alhambra, algún que otro bargueño estilo renacimiento español" además de "dos imágenes del Sagrado Corazón de Jesús policromadas". La llegada de los exiliados es narrada como el desarrollo de una (segunda) dominación colonial para la que la clase criolla oriunda colabora "con formidable habilidad en aquella empresa de creación febril -y no fabril" (1996: 140-141). Granell 
reprueba así la transposición de un modelo cultural europeo español a las tierras de acogida caracterizándolo en términos de conquista.

Víctor Fuentes ha calificado La Novela como parte de una literatura de un grupo de exiliados que, tras experimentar lo que en el ostracismo presupone el reverso simbólico del viaje de los antiguos conquistadores, huyendo de la retórica imperialista franquista, adoptan una postura anticolonialista (2000: 81). Esta opinión es compartida por Manuel Fernández Rodríguez, quien arguye que La Novela "representa unha subversión antropolóxica ante o etnocentrismo cultural occidental" (2006: 83). Lo que Granell denuncia en sus páginas constituye un fenómeno que ha sido denominado por Aníbal Quijano como "colonialidad de poder": una estructura de dominación que implica la hegemonía europea no sólo en términos espaciales sino en el "control de la subjetividad, de la cultura, y en especial (...) de la producción del conocimiento" (1993: 209). La identificación de la clase criolla con las categorías de poder europeas sería una consecuencia directa de esa colonialidad, que consiste en articular simbólicamente lo europeo como válido, resultando en una división racial de las clases sociales latinoamericanas (1993: 241).

Si bien para Quijano lo europeo no implica necesariamente la inclusión de lo español, Granell aglutina ambas categorías en la enumeración de los elementos arquitectónicos, escultóricos y decorativos elevados, y elabora la participación del colectivo criollo en esta empresa de acuerdo a su identificación con patrones hegemónicos de pensamiento diametralmente opuestos a los de los protagonistas. El indio y la gitana -cuya diferencia racial queda patente en la novela- son construidos como meros espectadores, capaces, sin embargo, de juzgar los acontecimientos. Precisamente por su carácter externo en la ejecución de cualquier tipo de dominación simbólica, ambos personajes representan voces autorizadas para legitimar o deslegitimar la cultura occidental, de entre cuyo corpus parece salvarse una única pieza: El Quijote. Como se afirma en La Novela: "no obstante de su origen, [el Indio] nada tenía en contra de lo que había de bueno en la madre patria de los conquistadores" (1996: 141).
La sátira granelliana se enfoca en el hispanismo atacando al que ha constituido uno de los argumentos tradicionales para justificar la ligazón simbólica entre España y sus antiguas colonias: la lengua. En el Carajá, un oriundo asegura la validez del idioma español no sólo como fuente de entendimiento entre distintas naciones hispánicas, sino como "ingenio de la raza" (1996: 141). La raza, categoría más espiritual que étnica, constituyó el motivo de celebraciones en los aniversarios del descubrimiento de América durante la II República, y siguió vigente durante el franquismo, que cambió el festivo a "Día de la Hispanidad". Mediante la alusión al concepto -y la lengua española como manifestación del mismo-, Granell realiza una crítica generalizada al colonialismo sin distinguir entre partidos políticos, etapas de la historia española, o bandos de la Guerra Civil. En otro pasaje de la novela, un intelectual llamado Don Pitágoras asegura tener padres españoles, si bien uno de los progenitores es de Bruselas. Ante la objeción de la gitana, quien apuntala que Bruselas está en Bélgica, Pitágoras responde: "Ya lo sé (...) pero no me negará usted que el reino de Flandes seguiría siendo español a no haber mediado la traición inglesa" (1996: 142). La escena ejemplifica lo que son dos constantes argumentales en La Novela: en primer lugar, la localización de las voces legitimadas en las minorías raciales que representan la gitana y el indio; en segundo lugar, una censura de la retórica del hispanismo y su asociación diacrónica a buena parte del campo de producción cultural español y latinoamericano. No es de extrañar que la crítica haya caracterizado a su protagonista como personaje "ultra-civilizado" en comparación con aquellos que protagonizaron la Guerra Civil (Irizarry 1984: 103); o haya destacado su superioridad intelectual al ser "o personaxe menos limitado a unha forma de ser e de estar no mundo" (Casas 2007: 97).

Si en los pasajes anteriormente citados la vituperación del hispanismo se produce sin alusiones específicas a un aparato institucional dado, la política exterior de Franco orientada a establecer relaciones de tipo cultural y comercial con América Latina es reseñada en la ficción de Granell con el nombramiento del 
Conquistador como cónsul y observador en el "nuevo mundo" (1996: 203). Los círculos intelectuales del régimen son también ridiculizados en una colaboración bidireccional entre España y el Carajá. El bardo carajeño Teddy Lincoln Zamora, quien debe su prestigio a la publicación de un soneto que poetiza la violación de una farmacéutica por parte de un cura (1996: 190), representa la personificación del vínculo entre ambas naciones cuando se le invita a España a dar una conferencia. En otra sección de la novela, se describen varios miembros del ambiente literario que caracterizaba las fiestas del Régimen: viejos hispanos enriquecidos que volvían a la "madre patria"; una serie de intelectuales latinoamericanos, "poetrastros" que "se asombraban del tono que sus cagarrutas cerebrales adquirían en el año solar al contraste de tantísimo estiércol"; junto a una masa de "gachupines" venidos de las Indias (1996: 149-151). Todos ellos forman parte del aparato simbólico intelectual del que se sirve la dictadura. La filiación hispanista de estos personajes se articula en forma de lo que Bourdieu ha denominado "habitus", un conjunto inconsciente de disposiciones, estructuradas y estructurantes, que generan y organizan prácticas, y que predisponen a entrar en un campo concreto (Johnson 1996: 5-8). En otras palabras: el hispanismo, en la novela de Granell, es construido como parte del habitus que dispone o autoriza a formar parte de la intelectualidad del Régimen.

La crítica al campo cultural de la dictadura continúa en la descripción de la "Academia de la Lengua y de la Ciencia”, puesta al servicio del entramado político franquista que en la ficción adquiere el nombre de "Máquina Científico-Moral". Ésta se caracteriza por el ejercicio de un control ideológico al que contribuyen los siguientes intelectuales ridiculizados: don Gregor (Gregorio Marañón), don Pepe Mari (José María Pemán), don Moncho (Menéndez Pidal), don Dama (Dámaso Alonso) y don Wences (Wenceslao Fernádez Flórez). La relevancia de esta crítica radica en la descalificación estética de su trabajo en cuanto connivente con el poder militar. Así, su labor se limitaría a "revisar el reglamento de la Guardia Civil o algún otro trabajo literario así, de los que daban gloria y dinero". Por último, la colaboración del universo letrado con el franquismo difunde los valores del Régimen en tierras latinoamericanas, como manifiesta el encuentro del Indio con el grueso de la intelectualidad española que se halla dando conferencias en el Carajá "pagados por zafios repulsivos dictadores" (1996: 164-73). Este pasaje corrobora el carácter transatlántico de la praxis cultural franquista al mismo tiempo que abre la puerta a la crítica de todo gobierno dictatorial.

\section{4. "UN MUNDO HISPÁNICO A LA DE- RIVA"}

En estos términos definió José Rubia Barcia la crítica que Granell efectúa en La Novela, yendo contra la corriente académica que insiste en calificar la obra únicamente como ficción sobre la Guerra Civil española. Por deriva entiende el autor toda guerra civil, pronunciamiento o acto de violencia de Estado (1961: 155). Sin dejar de establecer cierta hermandad utópica entre pueblos hispanos, Rubia da la clave de lo que la obra representa en cuanto crítica y rechazo de cualquier forma de autoritarismo, incluyendo la dictadura de Trujillo. La República del Carajá, pudiéndose considerar epítome de Latinoamérica, lugar imaginario de recepción de los exiliados que debe su nombre a una localización brasileña, no deja de representar, al fin y al cabo, la primera nación transatlántica que acogió a Granell: la República Dominicana. Javier Herrera destaca la paradoja de los exiliados que, al arribar a tierras dominicanas, "se asientan en el país más alejado de sus ideales socialistas y anarquistas" (2009: 196). En una novela que escudriña las relaciones de dominación política y simbólica entre España y Latinoamérica, Granell va a efectuar asimismo una crítica de aquellas medidas opresoras implementadas por el país que primeramente le dio asilo.

Una de ellas tiene que ver con las políticas de inmigración que permitieron la entrada a los exiliados españoles. Según Natalia González Tejera, la nación dominicana había impulsado desde finales del siglo XIX la llegada de pobladores foráneos para llevar a cabo la colonización agrícola de parte del territorio nacional aún sin explotar. Consecuentemente, 
en 1934 se promulga una ley que permitía la entrada de extranjeros que "además de ser aptos para las labores del campo, no tuvieran antecedentes penales y gozaran de buena salud, fueran de raza blanca" (2010: 81). Ello explica que cuando el gobierno de Trujillo decide admitir refugiados españoles, lo haga en calidad de colonos agricultores. La ridiculización de las políticas de blanqueamiento es objeto de la ironía del narrador granelliano, quien afirma que "habiendo abolido el país toda discriminación racial, era inútil pretender el visa alegando ser mestizo, criollo, mulato, siamés, sirio, ario, judío o vizcaitarra" (1996: 135). En otro pasaje, la ficción critica la condición de labrador -desempeñada por el propio Granell al llegar- que el emigrante debía fingir para conseguir su entrada a la nación dominicana:

\section{Lugar de nacimiento: Labriego. \\ Nombre de la madre: Labriego \\ Nombre del padre: Labriego. \\ Nombre del espíritu santo: Labriego (...) \\ Credo político: Labriego (...) \\ Casado, soltero (tache lo que no sirva): \\ Labriego. (1996: 137)}

Sin embargo, las razones más probables de que la dictadura admitiera la entrada de inmigrantes potencialmente subversivos están relacionadas con el panorama geopolítico, dentro del cual el régimen de Trujillo gozaba de una legitimidad cuestionable. Vicente Llorens explica en sus Memorias cómo el dictador precisaba lavar su mala prensa internacional después de la matanza de negros haitianos que había perpetuado en 1937, con la perspectiva de incrementar sus relaciones diplomáticas con Estados Unidos (1975: 196). Su acercamiento a la potencia económica se realizaba ante el peligro inminente de guerra mundial y es anterior al beneplácito norteamericano dado a la dictadura franquista por su aversión al comunismo en el marco de la Guerra Fría. La política de aproximación a Estados Unidos se lleva a cabo mediante la simulación de la praxis democrática que consistió, entre otras prácticas, en nombrar y deponer arbitrariamente a diferentes presidentes del gobierno, quedando éstos sometidos al mandato único de Trujillo. Consciente del artificio, Granell lo ficcionaliza mediante la narración de un error militar consistente en destituir al general que supuestamente debía gobernar la patria. El fallo se subsana de la siguiente forma:

Dado que ya era tarde para empezar de nuevo (...) lo que se hizo fue redactar sobre la marcha un decreto, por medio del cual el general depuesto pasaba automáticamente a llamarse como el general triunfante, y éste usaría, a la recíproca, en lo sucesivo, el nombre del general exonerado. (1996: 201)

En una escena que ha sido calificada por Irizarry como ejemplo de "imaginación humorística" (1976: 75), Granell hace partícipe al lector del funcionamiento de un régimen autoritario distinto al español, encuadrando la Guerra Civil y sus consecuencias en el contexto internacional de un universo hispánico cuya violencia simbólica, política e institucional se manifiestan, a los ojos del Indio, irreparables. Al final de la novela, el protagonista se esfuma en una elevación mítica tras haber intentado, sin éxito, dilucidar "algunas medidas para librar al mundo de los perjuicios con que lo amenazaba la civilización occidental" (1996: 178). Es esta imposibilidad de subvertir la historia, sin embargo, lo que lo ha conducido a la redacción de "su" novela. En ella queda patente la crítica al hispanismo como discursividad histórica de dominación simbólica y cultural de España sobre sus antiguas colonias; la connivencia de algunos sectores latinoamericanos con el imperialismo discursivo anterior usado como categoría de diferenciación social y racial; el carácter hegemónico del hispanismo concebido como elemento del habitus para acceder a determinadas posiciones del campo de producción cultural; $\mathrm{y}$, sobre todo, la necesidad de hacer visibles aquellas voces disidentes que, como la del propio Granell, sean capaces de efectuar una crítica políticamente transversal, internacional y ética de toda historia a la deriva. 


\section{REFERENCIAS BIBLIOGRÁFICAS}

Bourdieu, Pierre (1993): The Field of Cultural Production: Essays on Art and Literature. New York: Columbia University Press.

Boza Puerta, Mariano y Miguel Ángel Sánchez Herrador (2007): “El martirio de los libros: una aproximación a la destrucción bibliográfica durante la Guerra Civil", Boletín de la Asociación Andaluza de Bibliotecarios 86/87, pp. 79-95.

CASAS VALES, Arturo (2006): “Antricrónica e subalternidade en 'La Novela del Indio Tupinamba'”, en Actas del Congreso Interdisciplinar Eugenio Granell (Santiago de Compostela, 25-27 abril 2006). Santiago de Compostela: Fundación Eugenio Granell, pp. 91-116.

DíAz Quiñones, Arcadio (2006): Sobre los Principios: los Intelectuales Caribeños y la Tradición. Bernal: Universidad Nacional de Quilmes Editorial.

Escudero, María A. (1994): El Instituto de Cultura Hispánica. Madrid: Editorial MAPFRE.

FABER, Sebastiaan (2000): "Contradictions of Left-Wing Hispanismo: The Case of Spain Republicans in Exile", Journal of Spanish Cultural Studies 3.2, pp. 165-185.

- (2002): Exile and Cultural Hegemony: Spanish Intellectuals in Mexico, 1939-1975. Nashville: Vanderbilt University Press.

FABer, Sebastián y Cristina MARTínez CARAzo (eds.) (2009): Contra el Olvido: el Exilio Español en Estados Unidos. Alcalá de Henares: Instituto Franklin de Estudios Norteamericanos.

FERnÁNDEz RodríGuez, Manuel (2006): “O Indio Interior de Eugenio Granell”, en Actas del Congreso Interdisciplinar Eugenio Granell (Santiago de Compostela, 25-27 abril 2006). Santiago de Compostela: Fundación Eugenio Granell, pp. 77-90.

FoucAult, Michel (200723): La Arqueología del Saber. Madrid: Siglo XXI.

Fuentes, Víctor (2000): “Arredor da Narrativa Galega no Exilio”, Grial. Revista galega de cultura 145 , pp. 71-87.

GonzÁlez Tejera, Natalia (2010): “Las Colonias de Refugiados Españoles en la República Dominicana, 1939-1941”, en R. Rosario Fernández (ed.), El Exilio Republicano Español en la Sociedad Dominicana: Seminario Internacional, Marzo 2010 (actas). Santo Domingo: Comisión Permanente de Efemérides Patrias, pp. 79-100.

Granell, Eugenio F. (1996): La Novela del Indio Tupinamba. Sada: Ediciós do Castro. (2001): La Novela del Indio Tupinamba. Sada: Ediciós do Castro.

Herrera, Javier (2009): “Figuras Lógicas y Figuras Visuales del Exilio Americano. Una Lectura de Umbral de Sueños de José Rubia Barcia y Dibujos de Eugenio F. Granell (con Luis Buñuel al Fondo)", en S. Faber y C. Martínez Carazo (eds.), Contra el Olvido: el Exilio Español en Estados Unidos. Alcalá de Henares: Instituto Franklin de Estudios Norteamericanos, pp. 187206.

IrIZARrY, Estelle (1976): La Inventiva Surrealista de E. F. Granell. Madrid: Ínsula. (1984): Writer-Painters of Contemporary Spain. Boston: Twayne.

Johnson, Randal (ed.) (1993): "Editors's Introduction: Pierre Bourdieu on Art, Literature and Culture", en P. Bourdieu, The Field of Cultural Production. New York: Columbia University Press, pp. 1-25.

Llorens, Vicente (1975): Memorias de Una Emigración: Santo Domingo, 1939-1945. Barcelona: Ariel. 
(1996): "Nota introductoria", en Eugenio F. Granell, La Novela del Indio Tupinamba. Sada: Ediciós do Castro.

LOUREIRO, Ángel (2003): "Spanish Nationalism and the Ghost of Empire", Journal of Spanish Cultural Studies 4.1, pp. 65-76.

Marra-López, José R. (1963): Narrativa Española Fuera de España, 1939-1961. Madrid: Ediciones Guadarrama.

Moreno Caballud, Luis (2009): "Viaje al Centro del Horror: Surrealismo, Humor y Destrucción en La Novela del Indio Tupinamba, de Eugenio F. Granell", Anales de la Literatura Española Contemporánea 34.1, pp. 159-183.

Navarro, Santiago Juan (2006): “'Una Sola Fe en Una Sola Lengua’: La Hispanidad como Coartada Ideológica en el Pensamiento Reaccionario Español”, Hispania 89.2, pp. 392-399.

PIKE B., Fredrick (1971): Hispanismo, 1898-1936. Spanish Conservatives and Liberals and Their Relations with Spanish America. Notre Dame: University of Notre Dame Press.

Quijano, Aníbal (1993): “Colonialidad de Poder, Eurocentrismo y América Latina”, en E. Lander (ed.), La Colonialidad del Saber: Eurocentrismo y Ciencias Sociales. Perspectivas Latinoamericanas. Buenos Aires: CLACSO, pp. 201-246.

Rubia Barcia, José (1961): "Eugenio F. Granell: 'La Novela del Indio Tupinamba”, Revista Hispánica Moderna 27.2, pp. 154-155.

SAID, Edward W. (2000): Reflections on Exile and Other Essays. Cambridge, Massachusetts: Harvard University Press.

Tovar, Francisco (ed.) (2001): "Las Figuras de Granell: Colores y Sugerencias", en E. Granell, La Novela del Indio Tupinamba. Sada: Ediciós do Castro, pp. 7-50. 